\title{
The use of V02 and VCO2 to optimise respiratory support and to wean mechanically ventilated patients after major abdominal surgery
}

\author{
MV Petrova*, SD Beeharry, AV Butrov, R Mohan, OL Bessolitsina \\ From ESICM LIVES 2015 \\ Berlin, Germany. 3-7 October 2015
}

\begin{abstract}
Introduction
The incidence of patients requiring ICU admission is as high as $32-55 \%$ after major abdominal surgeries due to severe abdominal complications. Mechanical ventilation is sometimes necessary during intensive treatment. Prognosis remains poor with mortality rate of $29-42 \%$. Success in weaning from mechanical ventilation in these patients remains a big problem.
\end{abstract}

\section{Objectives}

To use V02 and VC02 (indirect calory parameters) to optimise respiratory support and to wean patients from mechanical ventilation.

\section{Methods}

26 patients after major abdominal surgery requiring Mechanical ventilation (11 women and 15 men with an average age of $52.4 \pm 9.2$ ) were randomly selected, from mid of 2014 to 2015. Patients were on mechanical ventilation for a at least 5 days. Engstrom Carestation Indirect Calorimeter's gas analyser (E-COVX) was used to measure the changes in oxygen consumption (V02) carbon dioxide production (VC02) on different modes of mechanical ventilation with stepwise reduction of mandatory breaths in Bi-level mode (from 12 to 6) with Pressure support of $16 \mathrm{~mm} \mathrm{H}_{2} \mathrm{O}$, followed by continuous positive airway pressure (CPAP/PSV) mode with decreasing Pressure support from 16 to $6 \mathrm{~mm} \mathrm{H}_{2} \mathrm{O}$ was used as weaning method. Cardiac output was also measured using bio-impedance method. Weaning procedure lasted 20-24 hours with changes in parameters noted every $2-3 \mathrm{hrs}$.

\section{Results}

The V02 and VC02 of patients in Bi-level mode were of $255 \pm 38 \mathrm{ml} / \mathrm{min}$ and $188 \pm 32 \mathrm{ml} / \mathrm{min}$ respectively. In weaned patients, a slight increase in $\Delta \mathrm{V} 02$ of $23 \pm 4 \mathrm{ml} /$ min $(9.1 \%)$ and significant increase in $\triangle \mathrm{VC} 02$ of $31 \pm$ $5 \mathrm{ml} / \mathrm{min}$ (16.5\%) occurred gradually with the decrease in pressure support. An insignificant increase in cardiac output from $3.6 \pm 0.4 \mathrm{l} / \mathrm{min}$ to $3.9 \pm 0.4 \mathrm{l} / \mathrm{min}$ was noted. 16 out of 26 patients were successfully weaned but in 6 of them mechanical ventilation had to be restarted. 10 patients could not be weaned at all and their $\Delta \mathrm{V} 02$ was of $77 \pm 10 \mathrm{ml} / \mathrm{min}(30.1 \%)$ and $\Delta \mathrm{VC} 02$ was of $54 \pm$ $7 \mathrm{ml} / \mathrm{min}(28.7 \%)$. These changes was also related with significant decrease in cardiac output to $3.1 \pm 0.3 \mathrm{l} / \mathrm{min}$.

\section{Conclusions}

Changes in $\triangle \mathrm{V} 02$ and $\triangle \mathrm{VC} 02$ parameters during weaning may be used as an alternate to Arterial blood gas analysis as they respond quicker to respiratory and metabolic distress. Thus, patients ventilator parameters could be altered accordingly in time without any significant respiratory and cardiac decompensation.

Published: 1 October 2015

doi:10.1186/2197-425X-3-S1-A315

Cite this article as: Petrova et al:: The use of V02 and VC02 to optimise respiratory support and to wean mechanically ventilated patients after major abdominal surgery. Intensive Care Medicine Experimental 2015

3(Suppl 1):A315. 